\title{
Gas Dynamics of Working Fluid Inlet into Chamber of Rotary Expansion Machine
}

\author{
Andrey Perminov \\ Department of Electric Coupling and \\ Automation Systems \\ Pskov State University \\ Pskov, Russia \\ alp-mail@mail.ru \\ Dmitriy Fedorov \\ Department of Electric Coupling and \\ Automation Systems \\ Pskov State University \\ Pskov, Russia \\ dmitriy-fedorov-2012@mail.ru
}

\author{
Alexander Ilyin \\ Department of Electric Coupling and \\ Automation Systems \\ Pskov State University \\ Pskov, Russia \\ al.ilyin@yandex.ru \\ Sergey Drozdov \\ Department of Electric Coupling and \\ Automation Systems \\ Pskov State University \\ Pskov, Russia \\ sergei_drozdov@inbox.ru
}

\author{
Sergey Tikhonov \\ Department of Automobile Transport \\ Pskov State University \\ Pskov, Russia \\ sit42@rambler.ru
}

\begin{abstract}
In this article, a mathematical model of working fluid inlet into chamber of rotary expansion machine from source of superheated steam. The main practical problem that can be solved on the basis of this model is to determine dependence of torque on the angular velocity, i.e. in the construction of mechanical characteristics of rotary expansion machine.
\end{abstract}

Keywords - rotary expansion machine; gas dynamics; mathematical model.

\section{INTRODUCTION}

Rotary vane and rotary machines have a number of advantages over engines of other designs, for example, connecting rod and piston: lower specific gravity, high specific liter power, can work stably at low speeds, less mechanical losses due to the absence of reciprocating movements, significantly less vibration due to design balance score. When implementing a thermodynamic cycle in a rotary machine with an external heat supply, it is possible to achieve high efficiency values, use various types of fuel, and ensure high environmental friendliness. Work on the development of engines and installations based on machines of rotary blade and rotary type has been carried out by the research team of Pskov State University for more than ten years, and the main research results are published in [2], [3], [8] - [15].

The subject of this article is a rotary expansion machine (patent RU 2619391 [1]). The device and the principle of operation of the rotary expansion machine are described in detail in [4], [5].

\section{INITIAL RELATIONS}

A diagram of the process of filling the chamber with a fresh gas charge is shown in Fig. 1. It is assumed that in the source from which the charge enters the chamber, it is maintained constant values of pressure $p_{0}$ temperature $T_{0}$ and isobaric heat capacity $c_{p 0}$ [6], [7].

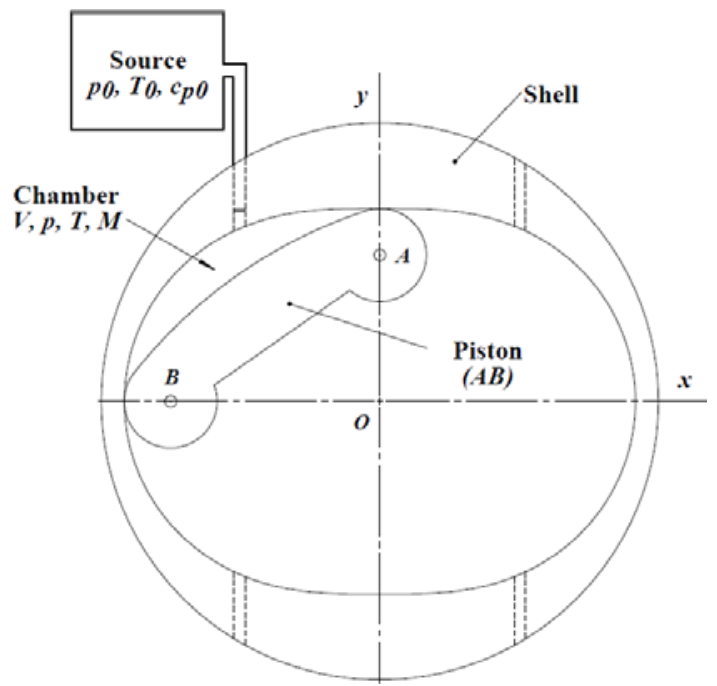

Fig. 1. Chamber inlet scheme. 
The gas enters the chamber through inlet port, flow area of which $f(\alpha)$ is a known function of shaft rotation angle $\alpha$. The dependence of chamber's volume $V(\alpha)$ on the angle, and angle of beginning of opening $\alpha_{B O}$ and angle of end of closing $\alpha_{E C}$ of inlet window are also set.

In this process, three variables are unknown: the pressure $p$ of gas in chamber, its mass $M$ and temperature $T$.

We will assume that gas flow, which has enthalpy $i_{0}=$ $c_{p 0} T$ and velocity $v$ at entrance to chamber, slows down inside chamber. The enthalpy of stalled flow increases by $v^{2} / 2$ and becomes equal to

$$
i_{0}^{*}=c_{p 0} T_{0}+v^{2} / 2
$$

Assuming that intake process is quasi-stationary, we will use the first law of variable mass thermodynamics to describe it. According to him, enthalpy flow entering chamber along with mass flow goes to change internal energy of gas and perform expansion work:

$$
i_{0}^{*} d M-d Q_{W}=d(M u)+p d V,
$$

where $u=c_{V} T$ is the specific internal energy of gas $\left(c_{V}\right.$ is isochoric heat capacity); $d Q_{W}$ is heat removed as a result of heat exchange of gas with chamber walls. form:

Equation (3) taking into account (1) is reduced to the

$$
\begin{gathered}
\left(c_{p 0} T_{0}+v^{2} / 2\right) d M=M c_{V} d T+c_{V} T d M+p d V+ \\
d Q_{W} .
\end{gathered}
$$

Next, we perform following transformations of this equation.

We divide both sides of Eq. (3) by the internal energy $M c_{V} T$ of the gas in the chamber and write it in the form

$$
\frac{d T}{T}=\left(\frac{c_{p 0} T_{0}+v^{2} / 2}{c_{V} T}\right) \frac{d M}{M}-\frac{p d V}{M c_{V} T}-\frac{d Q_{W}}{M c_{V} T} .
$$

Considering Mayer's formula for the gas constant

$$
R=c_{p}-c_{V}
$$

the equation of state is reduced to the form $p V=$ $\left(c_{p}-c_{V}\right) M T$, or

$$
p V=(k-1) M c_{V} T,
$$

where $k$ is the adiabatic exponent:

$$
k=\frac{c_{p}}{c_{V}} .
$$

Taking into account (6), the second term on right-hand side of equation (4) takes the form

$$
\frac{p d V}{M c_{V} T}=(k-1) \frac{d V}{V}
$$

and equation (4) is written as

$$
\frac{d T}{T}=\left(\frac{c_{p 0} T_{0}+v^{2} / 2}{c_{V} T}-1\right) \frac{d M}{M}-(k-1) \frac{d V}{V}-\frac{d Q_{W}}{M c_{V} T} .(9)
$$

Next, we will apply following mathematical trick. Let us take natural logarithm of both sides of equation of state $p V=R M T \quad: \quad \ln p+\ln V=\ln R+\ln M+\ln T$. Differentiating by angle of rotation of shaft $\alpha$, we obtain $\frac{1}{p} \frac{d p}{d \alpha}+\frac{1}{V} \frac{d V}{d \alpha}=\frac{1}{M} \frac{d M}{d \alpha}+\frac{1}{T} \frac{d T}{d \alpha}$, whence we find

$$
\frac{d T}{T}=\frac{d p}{p}+\frac{d V}{V}-\frac{d M}{M}
$$

Equating the right-hand sides of equations (9) and (10), we obtain

$$
\frac{d p}{p}=\frac{c_{p 0} T_{0}+v^{2} / 2}{M c_{V} T} d M-\frac{k}{V} d V-\frac{d Q_{W}}{M c_{V} T}
$$

Dividing (11) by differential $d \alpha$, we obtain the differential equation

$$
\frac{d p}{d \alpha}=p\left[\frac{{ }^{c_{p 0} T_{0}+v^{2} / 2}}{M c_{V} T} \frac{d M}{d \alpha}-\frac{k}{V} \frac{d V}{d \alpha}-\frac{1}{M c_{V} T} \frac{d Q_{W}}{d \alpha}\right]
$$

\section{FLOW RATE AND MASS CHANGE}

It is known that the flow at the chamber entrance has a velocity

$$
v=\varphi \sqrt{R T_{0}}
$$

where $R=c_{p}-c_{V}$ is gas constant; $\varphi$ is a factor that, depending on flow regime (subcritical or critical), takes on values

$$
\begin{array}{r}
\varphi=\sqrt{2 \frac{k}{k-1}\left[1-\left(\frac{p}{p_{0}}\right) \frac{k-1}{k}\right]} \text { for } p \geq p_{c r} ; \varphi= \\
\sqrt{2 \frac{k}{k+1}} \text { for } p<p_{c r} .(14)
\end{array}
$$

Here $k=c_{p} / c_{V}$ is the adiabatic exponent; $p_{c r}$ is critical value of pressure in the chamber

$$
p_{c r}=\beta_{c r} p_{0}, \beta_{c r}=\left(\frac{2}{k+1}\right)^{\frac{k}{k-1}}
$$

So, for diatomic gases $k=1.4$ and $\beta_{c r}=0.527$; for polyatomic gases and superheated steam $k=1.3$ and $\beta_{c r}=0.546$. At $p<p_{c r}$, the coefficient $\varphi$ for these gases takes on the values $\varphi=1.08$ and $\varphi=1.06$, respectively, while outflow velocity has a constant maximum value equal to speed of sound in this medium. 
Environment. Technology. Resources. Rezekne, Latvia Proceedings of the $13^{\text {th }}$ International Scientific and Practical Conference. Volume 3, 266-269

Let the intake port have an area $f_{0}$. In the processes of opening and closing the window, the area of its passage for gas section, which we denote by $f(\alpha)$, varies in range $0 \leq$ $f(\alpha) \leq f_{0}$. Then the second mass flow rate of gas through window is determined by formula

$$
\frac{d M}{M}=\mu \rho v f(\alpha)
$$

where $\rho=M / V$ is gas density; $\mu$ is the flow coefficient taking into account compression of jet and aerodynamic drag, approximate value of which is

$$
\mu \cong 0.37
$$

Taking into account that $d t=d \alpha / \omega$, the differential dependence follows

$$
\frac{d M}{d \alpha}=\frac{\mu}{\omega} \frac{M}{V(\alpha)} v f(\alpha)
$$

\section{EXHAUST HEAT}

During the time interval $d t$ of the working fluid through the chamber wall heat is removed

$$
d Q_{W}=\beta_{T} F\left(T-T_{W}\right) d t,
$$

where $\beta_{T}$ is instantaneous value of heat transfer coefficient by forced convection, averaged over current surface of walls with area $F ; T$ and $T_{W}$ are current temperatures of working fluid and walls, respectively.

The shaft rotates with an angular velocity $\omega=d \alpha / d t$. Since $d t=d \alpha / \omega$, the last term on the right-hand side of equation (12) takes the form

$$
\frac{1}{M c_{V} T} \frac{d Q_{W}}{d \alpha}=\frac{\beta_{T} F}{\omega M c_{V} T}\left(T-T_{W}\right) .
$$

\section{INTAKE EQUATIONS}

Adding the equation of state $p V=M R T$ to equations (12) and (18), we have a closed system of three equations for determining three unknowns $p, M, T$ as functions of angle $\alpha$ in range $0^{\circ} \leq \alpha \leq 90^{\circ}$.

$$
\left\{\begin{array}{c}
p V=M R T \\
\frac{d p}{d \alpha}=p\left[\frac{c_{p 0} T_{0}+v^{2} / 2}{M c_{V} T} \frac{d M}{d \alpha}-\frac{k}{V} \frac{d V}{d \alpha}-\frac{1}{M c_{V} T} \frac{d Q_{W}}{d \alpha}\right] \\
\frac{d M}{d \alpha}=\frac{\mu}{\omega} \frac{M}{V(\alpha)} v f(\alpha)
\end{array}\right.
$$

The initial conditions for solving these equations are values $p_{2}, M_{2}, T_{2}$ and $V_{2}$ of state of gas remaining after its previous release from this chamber.

\section{SIMULATION RESULTS}

The resulting system of equations was used to build a simulation model in the MatLab Simulation system. A series of computational experiments were carried out on the simulation model to confirm the adequacy of the obtained mathematical model. The results of the experiments are shown in Fig. 2-5. The results are presented in relative units for a shaft rotation speed of $31.42 \mathrm{rad} / \mathrm{s}$, working fluid is air, and calculated machine power is $10 \mathrm{~kW}$.

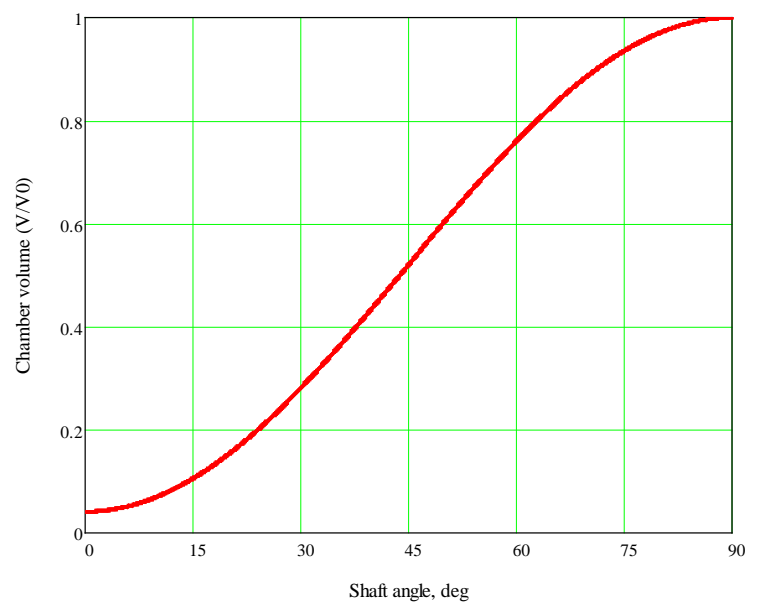

Fig. 2. Dependence of chamber volume on shaft angle.

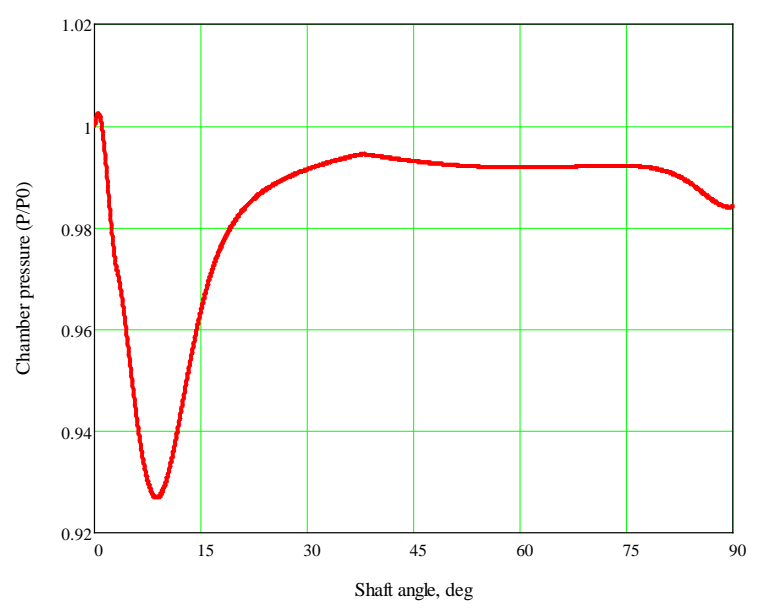

Fig. 3. Dependence of chamber pressure on shaft angle. 


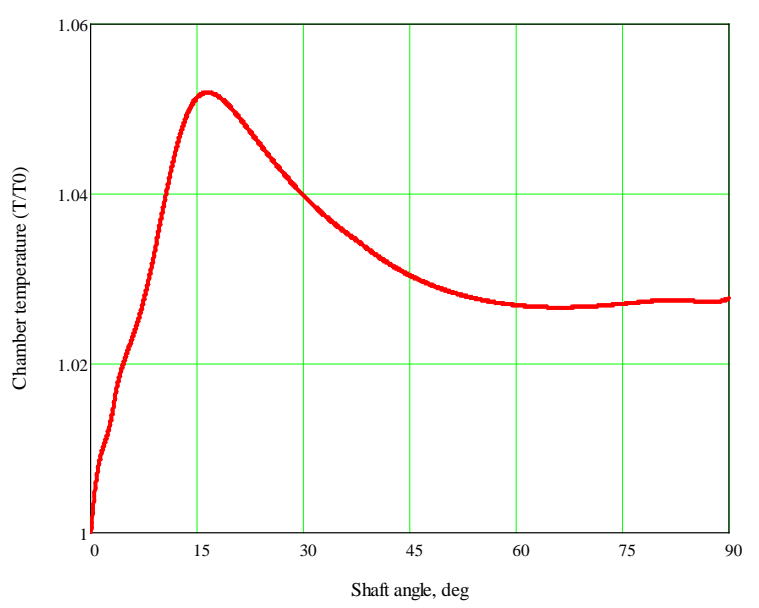

Fig. 4. Dependence of chamber temperature on shaft angle.

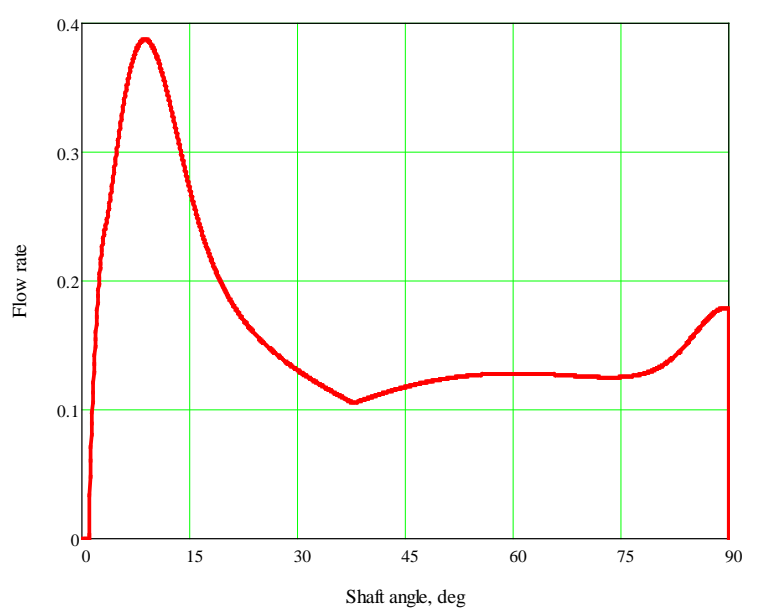

Fig. 5. Dependence of flow rate on shaft angle.

The resulting simulation model makes it possible to study the effect of various working fluids on the efficiency of a rotary expansion machine.

\section{CONCLUSION}

In this article, a mathematical model of process of admitting superheated steam from a heat source to chamber is constructed. In formulation of problem, an assumption was made, according to which superheated steam, being a real gas, is considered an ideal gas. This assumption allowed us to simplify the model, which can be useful as a first approximation.

The main practically necessary problem, which can be solved on basis of this model, is to determine dependence of torque on angular velocity, i.e. in construction of mechanical characteristics of a rotary expansion machine.

\section{REFERENCES}

[1] RF Patent 2619391 for an invention. Int. Cl. F01C1/44. Rotary Expantion Machine / Y.N. Lukyanov, Y.N. Zhuravlev et al. Publ. 15.05.2017.
[2] RF Patent 2374526 for an invention. Int. Cl. F16H25/04. Mechanism for converting motion / Y.N. Lukyanov, Y.N. Zhuravlev et al. Publ. 27.11.2009. Bull. Number 33.

[3] RF Patent 2387844 for an invention. Int. Cl. F01G1/077, F02G1/044. Rotary-vane engine with an external supply of heat $/$ Y.N. Lukyanov, Y.N. Zhuravlev et al. Publ. 27.04.2010. Bull. Number 12.

[4] Y.N. Zhuravlev, I.V. Plokhov, Y.N. Lukyanov, and others, Calculation and Design of Rotaty-blade Machine with External Heat Supply. Monogrphy. Pskov, 2012.

[5] Y. N. Zhuravlev, I. V. Plokhov, Y. N. Lukyanov, and others, Mathematical Models of Physical Processes in Rotary-blade Engine with External Heat Supply. Monogrphy. Pskov, 2012.

[6] Perminov A., Lukyanov Y., Ilyin A., Zhuravlev Y., Tikhonov S., Determination of chamber and piston geometry for a rotary type expansion machine. "Environment. Technology. Resources. Proceedings of the 12th International Scientific and Practical Conference", 2019, 3, стр. 197-200, https://doi.org/10.17770/etr2019vol3.4060

[7] Zhuravlev Y., Perminov A., Lukyanov Y., Tikhonov S., Ilyin A., Construction of piston outer profile for rotary type expansion machine. "Environment. Technology. Resources. Proceedings of the 12th International Scientific and Practical Conference”, 2019, 3, p. 257-260, https://doi.org/10.17770/etr2019vol3.4059

[8] S.Semyonov, S.Tikhonov, Y.Lukyanov, A.Perminov, Analysis method of calculation parameters of heat and mass transfer processes in the stirling engine. "Environment. Technology. Resources. Proceedings of the 11th International Scientific and Practical Conference”, 2017, 3, p. 298-303, https://doi.org/10.17770/etr2017vol3.2513

[9] S.Semyonov, S.Tikhonov, Y.Lukyanov, A.Perminov, Optimization of mechanical strength of rotary-vane engine. "Environment. Technology. Resources. Proceedings of the 11th International Scientific and Practical Conference”, 2017, 3, p. 357-360, https://doi.org/10.17770/etr2017vol3.2511

[10] Perminov A., Lukyanov Y., Tikhonov S., Ilyin A. Thermodynamic cycle with two-component working fluid. "Environment. Technology. Resources. Proceedings of the 11th International Scientific and Practical Conference”, 2015, https://doi.org/10.17770/etr2015vol2.261

[11] Y. N. Zhuravlev, A. L. Perminov, Y. N. Lukyanov, S. I. Tikhonov, S. N. Semenov, Minimization of Mechanical Strength of Rotaryblade Heat Engine with Cam-and-lever Motion Transformer. Bulletin of Pskov State University. Series: Engineering scinces, 2016.

[12] A. L. Perminov, A. A. Khitrov, A. I. Khitrov, Mechatronic System "Magneto-electric Synchro Motor - Active Rectifier" for Autonomous Energy Station Using Rotary-blade Machine with External Heat Supply. "Proceedings of VII International (VIII Russian) Conference on Automotization Electrical Drives AEP2012”, Ivanovo State Energy University, Ivanovo, 2012. P. 330335

[13] Andreev M., Zhuravlev Y., Lukyanov Y., Perminov A. Autonomous Power Station Based on Rotary-Vane Engine with an External Supply of Heat. Environment. Technology. Resources. Proceedings of the 9th International Scientific and Practical Conference. $\quad 2.2013$, https://doi.org/10.17770/etr2013vol2.842

[14] A.L. Perminov, Y.N. Lukyanov, S.I. Tikhonov, Electrogenerators fot Energy Sets. "Electrical Engineering. Electrical Energy. Information Techlogies. Proceedins of I International Research and Prctice Seminar”, Pskov. 2018. P. 52-55.

[15] Perminov A.L., Luk'yanov YU.N., Tikhonov S.I., Il'in A.V. Elektrogeneratory dlya energoustanovok. Elektromekhanika. Elektroenergetika. Informatsionnyye tekhnologii Sbornik materialov 1-go Mezhdunarodnogo nauchno-prakticheskogo seminara. 2018. pp. 52-55. 